\title{
Amor y sufrimiento, un análisis de un poema de María Enriqueta Camarillo.
}

\section{Love and suffering, an analysis of a poem by María Enriqueta Camarillo.}

Esta obra está bajo una Licencia Creative Commons Atribución 4.0 Internacional. DOI: $\underline{10.32870 / \text { sincronia.axxiii.n75.13a19 }}$

\author{
Carmina Alejandra García Serrano \\ Departamento de Letras \\ Universidad de Guadalajara \\ carminaburana74@hotmail.com \\ (MÉXICO)
}

\section{Irma Angélica Bañuelos Ávila}

Departamento de Letras

Universidad de Guadalajara

irmaisla@hotmail.com

(MÉXICO)

Recibido: $31 / 10 / 2018$

Revisado: $22 / 11 / 2018$

Aprobado: $27 / 11 / 2018$

\section{RESUMEN}

En el presente artículo se analizan la estructura, organización temática, tropos y figuras, dualidades y oposiciones, estructura climática y ritmo, rima y metro del poema Tornó mi dolor de la escritora mexicana María Enriqueta Camarillo con la finalidad de demostrar que esta escritora presenta en su creación una estructura organizada producto de una rigurosa planificación y se demuestra que el ritmo es el elemento modernista central que la autora pretende destacar. Por otra parte, se busca hacer evidente que todos los elementos analizados son un recurso para generar una estructura compleja para expresar una particular relación entre amor y sufrimiento y dolor. La metodología 
aplicada es de corte estructuralista y permite derivar modelos esquemáticos que sintetizan las estructuras: temática, climática, temporal, de campos léxicos, de ritmo, rima y métrica.

Palabras clave: Estructura. Unidad temática. Oposición. Campo léxico. Ritmo.

\begin{abstract}
In this article we analyze the structure, thematic organization, tropes and figures, dualities and oppositions, climatic structure and rhythm, rhyme and meter of the poem Tornó mi dolor by the Mexican writer María Enriqueta Camarillo in order to demostrate that this writer presents in its creation an organized structure product of a rigorous planning and demostrates that the rhythm is the central modernist element that the author pretends to highlight. On the other hand, it is sought to make evident that all the elements analyzed are a resource to generate a complex structure to express a particular relationship between love and suffering and pain. The applied methodology is structuralist and allows to derive schematic models that synthesize the structures: thematic, climatic, temporal, lexical fields, rhythm, rhyme and metric.
\end{abstract}

Keywords: Structure. Thematic unit. Opposition. Lexical field. Rhythm.

María Enriqueta Camarillo y Roa, nació en Coatepec el 19 de enero de 1872 y fue considerada como una de las primeras escritoras profesionales de México. Desde los 22 años comenzó a colaborar en las revistas y periódicos más importantes del México en que le tocó vivir. En este trabajo intentaremos mostrar cómo Enriqueta Camarillo reprodujo el discurso aceptado en su época y cómo en su yo poético aparece la voz de una mujer sumisa, resignada a su destino y observadora de las reglas sociales del siglo XIX y principios del siglo XX en los que tanto su poesía como su prosa triunfaron y fueron olvidadas casi al mismo tiempo. 
Seguramente es [...] la escritora mexicana con mayor número de juicios críticos y elogios de escritores extranjeros, la de más notas periodísticas y la que ha gozado del más alto reconocimiento en vida. Todo ocurrió en unos años; sus viajes, la difusión de sus obras, la exaltación de su estilo y, también, el olvido (Robles, Martha: 1986, p.100).

En la obra de Enriqueta se consideró la originalidad, la belleza y feminidad de la obra, pero sobre todo que esta no imitara a la literatura escrita por hombres. Tal fue su éxito que, en 1926, en la colección francesa Les cahiers féminins, cuyo objetivo era la difusión de textos escritos por mujeres le publicó su novela: El secreto, escrita en 1922, cuya traducción estuvo a cargo de Agatha Valery, hija de Paul Valery quien comentó sobre ella "La novela El Secreto de María Enriqueta es un hermoso y profundo libro de psicología admirable" (Contreras Romo, 2000, p.262).

No obstante, tanta fama, como se ha mencionado antes, esta fue efímera, su éxito fue fugaz, pero ¿Cuál o cuáles fueron las razones para que ello aconteciera? ¿Acaso su visión de mundo quedó desfasada, obsoleta ante el nuevo siglo? Es evidente que los versos de la autora están atravesados por las convenciones sociales de su tiempo, su discurso poético como luego se verá está organizado en torno del mito del eterno femenino, siempre sometido a la aprobación masculina.

La poesía de María Enriqueta, en general, nos ofrece un imaginario que reproduce la ideología esencialista que reduce a la mujer a la representación de lo emotivo, lo sentimental, o íntimo; en oposición a lo racional, lo exterior, "lo masculino". El universo semántico asimismo alude, en menor grado, al lugar asignado tradicionalmente a la mujer dentro de la sociedad: el hogar. (Contreras Romo: 2000, p 263).

En los versos de María Enriqueta nos encontramos casi siempre con un hablante poético en primera persona del singular; que se dirige a un oyente poético que corresponde regularmente a la segunda persona del singular, al amado y en otras a la segunda persona del plural, a una colectividad que comparte su sentir poético. El amor es el principal sentimiento al que le canta el sujeto lírico, el cual vinculará de manera obsesiva a la tristeza, al dolor, a la muerte o a su no realización. 
El poema “Tornó mi dolor" de María Enriqueta Camarillo, escrito en 1908, es el poema que hemos analizado para intentar mostrar primero cuáles son las unidades temáticas que lo estructuran y después revisar su correspondencia con la época y la visión de mundo todavía del siglo XIX. La estructura del texto se apoya en contrastes, que se pueden observar en los distintos niveles y planos. El poema dice así:

TORNÓ MI DOLOR

$$
\begin{gathered}
\text { Muerta ya en mi toda queja } \\
\text { y tranquila con mi olvido, } \\
\text { ayer, en una calleja } \\
\text { hirió de pronto mi oído } \\
\text { un canto tras una reja. } \\
\text { ¡Ah, de la triste canción } \\
\text { por tanto tiempo olvidada! } \\
\text { Desde ayer que oí su son } \\
\text { tengo una espina clavada } \\
\text { en medio del corazón. } \\
\text { (Camarillo, 1984, p. 88) }
\end{gathered}
$$

Como podemos observar, el poema no contiene metáforas novedosas: no es rebuscado, no hay simbolismos, el lenguaje y las figuras son comunes y sencillas, pero es muy musical debido al ritmo de los versos, y lo más importante de todo es que el tema principal del poema es muy común al ser humano. A casi todo el mundo en la vida le ha sucedido que una canción le traiga repentinamente un recuerdo inesperado. El amor es, en general, el tema predilecto de la canción y la mayoría de las parejas de enamorados tienen lo que denominan "su canción".

Lo singular de este poema no radica en grandes aportes metafóricos o en una estructura compleja y rebuscada, sino en la universalidad de la temática que toca. El hecho de que el poema 
sea sencillo nos permitirá enfocarlo de una manera general, porque no es un poema extenso, no tiene metáforas rebuscadas, ni estructuras complejas. Pero esto que comentamos no es un defecto del poema sino, por el contrario, el elemento donde radica su genialidad:

1. Contenido y lenguaje no elitistas accesibles a un público de cultura y educación medias (básica o superior).

2. La anteriormente comentada universalidad del tema:

a) Los enamorados tienen una canción.

b) La música nos recuerda una época.

c) Las personas asocian canciones con situaciones.

Nuestro objetivo es llevar a cabo un análisis del poema Tornó mi dolor que nos permita visualizarlo desde diversas perspectivas para poder valorarlo de forma integral:

1. Estructura del poema

2. Organización temática

3. Tropos y figuras

4. Dualidades y oposiciones

5. Estructura climática

6. Ritmo-Rima-Metro

El objetivo es detectar los elementos más relevantes que una autora del siglo XIX tomó en cuenta para escribir un poema. Se trata de señalar que, en un poema tan sencillo, hay una estructura y toda una serie de elementos (enumerados arriba) que se relacionan sistemáticamente para dar origen a un poema. Trataremos de demostrar que el texto es fruto de la planeación y de la interrelación consciente de sus elementos descubriendo así la estrategia de creación que María Enriqueta utilizó en este poema.

Iniciaremos comentando que en el texto encontraremos dos actores líricos, el hablante lírico marcado en la primera persona (es un "yo") y la canción, que se establece en la esfera de la nopersona ("ella"). El motivo temático nuclear se localiza en los versos 6-7 (“iAh, de la triste canción 
por tanto tiempo olvidada!") y es el recuerdo, algo que estuvo ausente de la memoria por mucho tiempo el que se manifiesta. Este es el eje temático horizontal, que está asociado a dos complementos de estado emocional y a uno de causa. Distinguiremos entre un estado emocional inicial (versos 1-2) y uno final (versos 8-10); el primero es de tranquilidad y el segundo de dolor. El complemento de causa (versos 3-5): oír un canto, es lo que desencadena el recuerdo.

El hablante lírico es un agente que se idéntica como femenina ("tranquila") cuyos atributos emocionales se contrastan a partir de un antes de oír la canción (tranquilidad) y un después de oírla (dolor). La canción es el agente que provoca esta dualidad de sentimientos, no es escuchada sino sentida, hiere. Se le adjudica el atributo "triste". El hablante lírico es un sujeto que cambia de estado de ánimo por la intervención del sujeto de la canción, que la hiere con el recuerdo. Por lo que podría plantearse una función de destinador del recuerdo a la canción y la de destinatario al hablante lírico. "Un texto tal como aparece en su superficie o (manifestación) lingüística, representa una cadena de artificios expresivos que el destinatario debe actualizar" (Páez Vivanco: 1988, p.73). La estructura del poema que se propone aquí se compone de 4 partes:

1. Estado emocional inicial (de no-dolor) [versos 1-2]

2. Inicio de la etapa de dolor [versos 3-5] (escuchar la canción)

3. El recuerdo [versos 6-7] (la canción se define como conocida)

4. Estado emocional final (de dolor) [versos 8-10]

Para analizar cada una de las partes que conforman la estructura, utilizaremos el concepto de Unidad Temática (UT), que tomamos de la teoría de Echenique (1997), la cual consiste en la agrupación de todos aquellos elementos afines a un mismo tema que confluyen en un mismo espacio textual (verso(s), estrofa(s)). Del foco temático (tema principal, alrededor del cual gira el resto de los temas) y sus complementos se derivan cuatro unidades temáticas (UT), cada una correspondiente a una de las cuatro partes en que se descompone la estructura del poema. Cada UT se distinguirá con un número acorde a su orden de aparición en el texto:

1. Estado de no-dolor UT1 [versos 1-2] 


\section{Canción $=$ dolor UT2 [versos 3-5]}

3. El recuerdo UT3 [versos 6-7]

4. Estado de dolor UT4 [versos 8-10]

Ahora, trataremos de explicar de qué elementos consta cada UT y cuál es la función de cada uno dentro de la unidad:

La UT1 (verso 1-2) marca el estado de no-dolor: queja, muerta, tranquilidad son atributos que el hablante lírico se adjudica para definirse, el olvido es lo que le permite permanecer así. No hay signos de puntuación que corten la fluidez de los dos versos que la componen. Son dos los requisitos que aquí se plantean para mantener ese estado de no dolor: la ausencia de quejas (verso 1) y la tranquilidad que da el olvido (verso 2). El hecho de que estos dos requisitos se presenten en versos diferentes les otorga cierta autonomía, además entre ellos no mantienen una relación de causa efecto, sino que la conjunción copulativa que los une proporciona una idea de adición / acumulación. Ambos son necesarios para mantener ese estado de no-dolor, cada uno conforme una sub-unidad temática.

En la UT2 (versos 3-5) se marca el inicio de la etapa de dolor. El verbo "hirió" implica un sema de dolor. Las circunstancias de esta nueva etapa son de tipo locativo y temporal. El adverbio ayer contrasta con el presente de la enunciación lírica que se define como un "hoy". Las circunstancias de lugar se manejan con un matiz de indefinición: en una calleja, tras una reja; los artículos indeterminados eliminan la posibilidad de una ubicación precisa. El canto que hiere actúa en circunstancias indefinidas: no se sabe quién lo emite ni el lugar preciso donde se emite, ni la finalidad, simplemente provoca dolor sin intención. El canto es un agente que carece de motivos, sus efectos se derivan de su esencia. Canto posee un sema auditivo por eso hiere en el oído (sentido y no parte del cuerpo).

La UT3 (versos 6-7) se definen como el recuerdo (de la canción triste por tanto tiempo olvidada), a partir de que se manifiesta el hablante lírico pierde los atributos que tiene en la UT1 y 
pasa al estado final (UT4). Recuerdo y canción se identifican con triste, donde el desplazamiento que se está haciendo del calificativo de la persona a la no-persona es de índole emocional.

UT4 (versos 8-10) define el estado emocional final: el dolor; lo hace por medio de una figura: una espina clavada en medio del corazón. Espina es un agente de la naturaleza e implica semas de dolor, lo que permite comprender por qué el canto hiere en UT2. El adverbio ayer (antecedido por la preposición desde vuelve a aparecer para marcar el tiempo en el que inició la etapa de dolor. Aquí (como en UT2) el tiempo está también definido en contraste con el tiempo de la enunciación (hoy).

La función de UT1 es definir el "yo" antes de la canción y UT4 lo define después de la canción. UT3 y UT2 mantienen entre sí una relación de causa-efecto abarcando la parte media del poema, y son necesarias para que se pueda presentar la metamorfosis de UT1 a UT4. Las Unidades Temáticas 1 y 4 guardan una relación funcional simétrica de inicio-fin del poema, son una especie de introducción y conclusión. Definen las etapas no-dolor y dolor. Los elementos que hemos mencionado conforman un cuadro de dualidades antitética en el nivel de relaciones y funciones de las unidades temáticas:

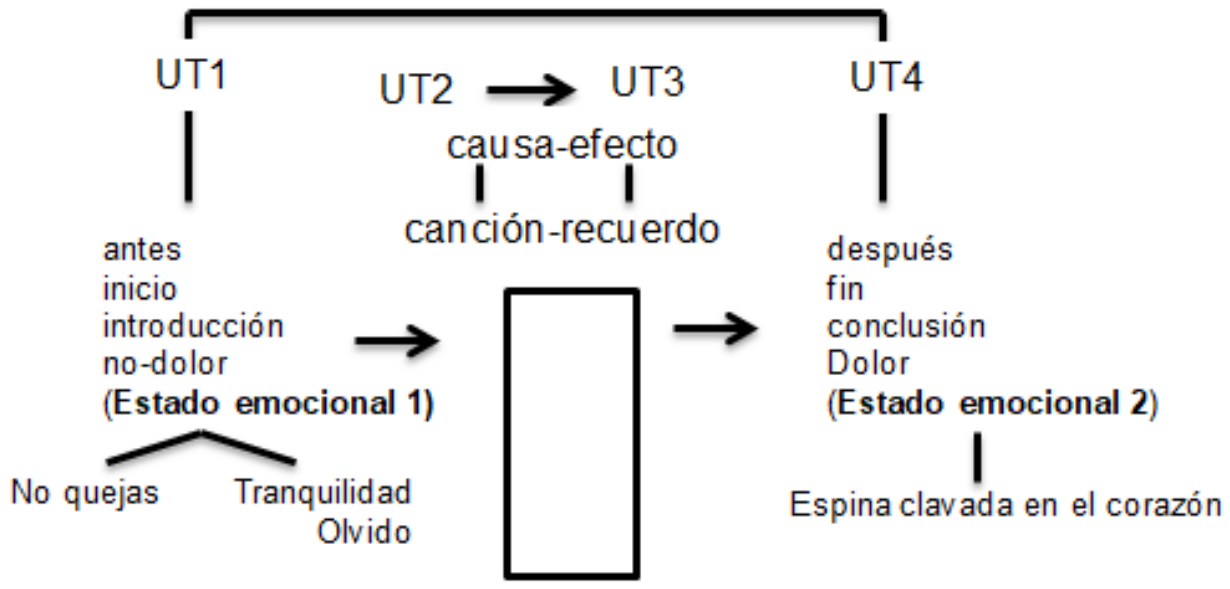

Esquema 1: Las unidades temáticas

(Fuente: Elaboración propia) 
El poema se compone de una sola estrofa que temáticamente podemos organizar en número de versos 2-3-2-3 y que temporalmente se divide en tres etapas $(A, B, C)$ :
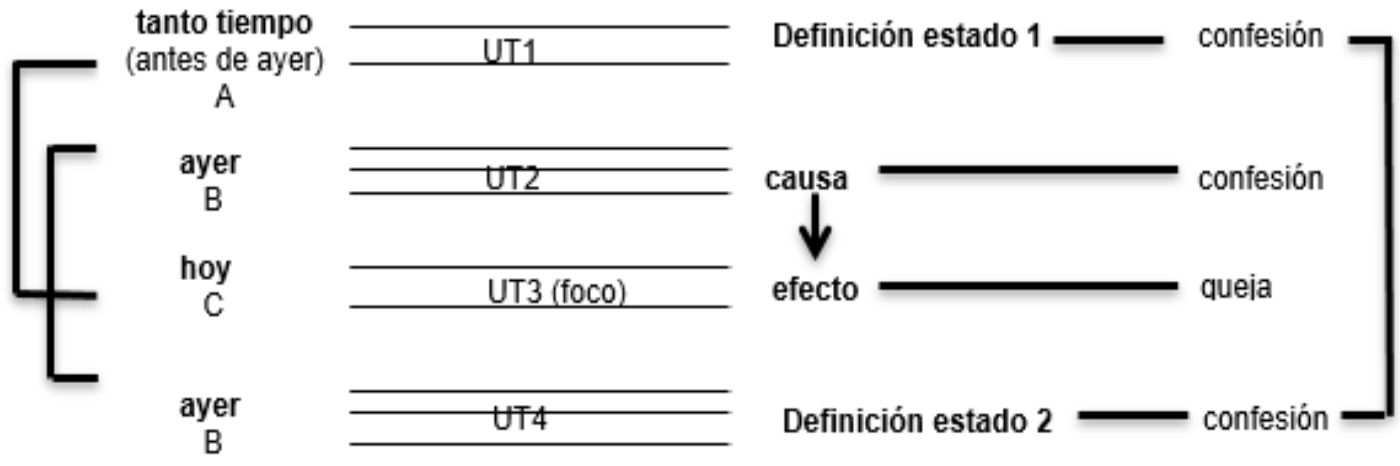

\section{Esquema 2: Organización temática}

(Fuente: Elaboración propia)

Las unidades temáticas 1, 2 y 4 comparten un tono de confesión, el foco temático se da en un tono de queja, entre exclamaciones. Los bloques centrales están interrelacionados por una relación de causa-efecto y el bloque inicial y final comparten la función de definir, marcan la evolución de un estado emocional del hablante lírico. Por el contrario, los bloques centrales centran su atención en el actor canción, enmarcan las circunstancias temporales y locativas de su acción, se presenta en un ayer pero sus efectos se prolongan hasta el hoy y se manifiestan en una queja. El bloque 2 y el 4 mantienen una liga temporal: lo que sucedió ayer (pretérito) y lo que sucede desde ayer: un efecto que tuvo su origen en el pasado pero que se prolonga hasta el presente "tener una espina clavada", el tiempo verbal en presente, en contraste con el adverbio de pasado, es la pauta que nos permite afirmar esto. Los bloques 1 y 3 también mantienen una liga temporal, pues en 3 se estipula el tiempo de duración de 1: la triste canción por tanto tiempo olvidada. La tranquilidad se mantuvo mientras duró el olvido, o sea, "tanto tiempo".

En la UT3 se manifiesta el más alto grado de emoción del poema: la queja. UT1 y UT4 son anticlimáticos, la primera por ser de tipo introductorio y preparativo, la segunda porque se presenta 
inmediatamente después del clímax y al no tener su mismo grado de intensidad hace descender la escala emotiva. UT2, que se presenta después de la parte introductoria, se eleva en la escala de emoción pues hace referencia a una herida. Podemos esquematizar así la estructura climática:

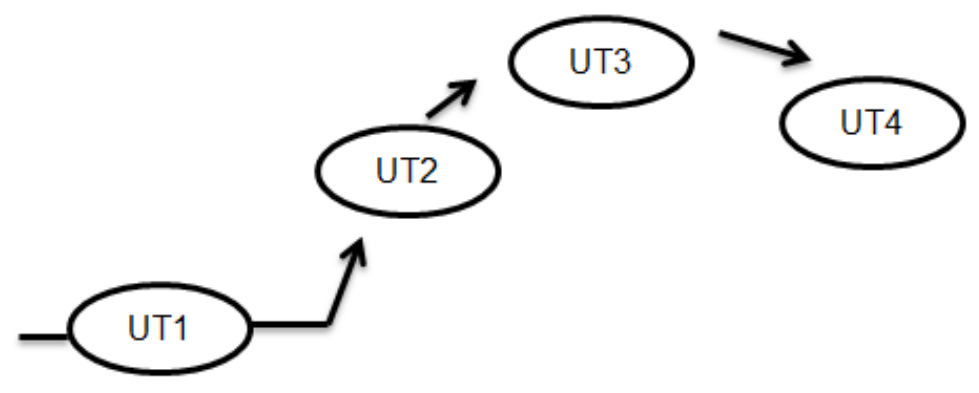

Esquema 3: La estructura climática

(Fuente: Elaboración propia)

El lenguaje del poema puede ubicarse en una norma media (no es vulgar ni culto). El enunciador del discurso poético es el hablante lírico, el enunciatario no aparece marcado en el texto y predomina el tono de confesión en el que se intercala el de queja.

Los Tropos y figuras que encontramos en el texto son:

- El apostrofe lo encontramos en la queja, que aparece entre signos de exclamación (expresa pasión) y en ella el emisor de la enunciación parece dirigirse así mismo acerca de algo que sólo él sabe en ese momento.

- Encontramos figuras de pensamiento como la prosopopeya cuando se le atribuye la cualidad de muerta a la queja. Canto y son aparecen como efectos de la canción, pero se toman por ésta para evitar la repetición y así se produce metonimia.

- La sinestesia se presenta por la contaminación de los sentidos del oído y del tacto: cantohiere. 
- Únicamente observamos una metáfora, que se da por la transferencia de nombre de una cosa a otra: una espina clavada en medio del corazón, espina aparece por dolor y corazón por un sentimiento o el lugar donde se siente el amor y el dolor de amor.

- Los primeros cinco versos se pueden definir como una unidad gramatical: una oración, en cuya estructura se manifiesta el hipérbaton: el circunstancial de modo compuesto, el de tiempo y el de lugar se presentan antes del verbo y del sujeto mismo. Entre el verbo y el sujeto se interpone, a su vez otro circunstancial de modo.

En el aspecto semántico podemos decir que la distribución léxica se da en cuatro campos:

- Auditivo (canto, canción, son, oído, oí)

- Dolor (hirió, triste, espina, clavada)

- Memoria (olvido, olvidada, tiempo, ayer)

- Corporal (mí (todo el ser), oído, corazón)

Entre el campo léxico auditivo y el de dolor se plantea una relación de causa-efecto (se siente dolor porque se oye). Entre el campo léxico de la memoria y el del dolor también se plantea la relación causa-efecto (se siente dolor porque se recuerda). Lo auditivo está incluido en lo corporal. El campo del dolor se presenta como abarcador de la memoria y de lo corporal: el dolor se manifiesta en el cuerpo (oído, corazón) y el recuerdo es dolor. Las relaciones entre estos cuatro campos se pueden esquematizar así: 

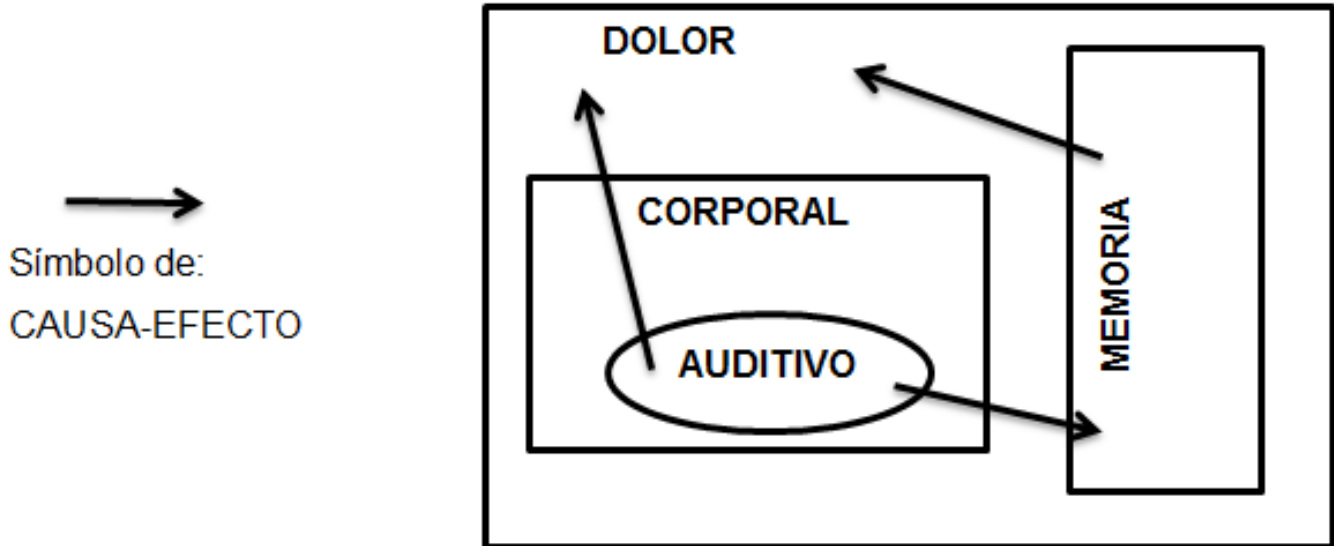

Esquema 4: Relación entre campos semánticos

(Fuente: Elaboración propia)

A lo largo del análisis encontramos dualidades antitéticas y contrastes. En cuanto a la tematización se manifestaron el estado de no-dolor / estado de dolor (inicial / final) que tienen su origen en la bina olvido vs recuerdo. Las unidades temáticas se articulan a partir de un antes (UT1) y después (UT4) de la canción y en la relación causa-efecto que guardan UT2 y UT3 entre sí. UT1 y UT2 tiene funciones contrarias: de apertura (introducción) y cierre (conclusión) respectivamente.

Semánticamente, el olvido está marcado como positivo y el recuerdo como negativo. El primero provoca tranquilidad, el segundo acarrea dolor. El contraste entre queja, que al estar muerta no siente, simboliza el no-dolor, y espina clavada, que actualiza semas de dolor. Ambos elementos son los definidores de los dos estados emocionales que se plantean. En cuanto al ritmo (como en seguida veremos) se nos presentan las dualidades lento / rápido que se relacionan con los temas graves / suaves.

Para finalizar, se presenta un análisis del ritmo, la rima y la métrica. Se puede apreciar la métrica (señalada por medio de diagonales), la rima (señalada por subrayado y por literales) y el ritmo (señalado por medio de negritas), el número de verso se señala a la izquierda de cada verso con número: 
Tornó mi dolor

1. Muer/ta/ ya en/ mil to/da que/ja

2. $\mathrm{y} / \mathrm{tran} /$ qui $/ \mathrm{la} \mathrm{con} / \mathrm{mi}$ ol$/ \mathrm{vi} / \mathrm{do}$,

3. $\mathrm{a} / \mathbf{y e r} / \mathrm{en} / \mathbf{u} / \mathrm{na} \mathrm{ca} / \mathrm{le} / \mathrm{la}$

4. hi/rió/ de/ pron/to/ mi o/i/do

5. un/can/to/ tras/ u/na/re/[a

6. ¡ $\mathrm{Ah} / \mathrm{de} / \mathrm{la}$ tris/te can/ción +1

7. por/tan/to/ tiem/po ol/vi/da/da

8. Des/de a/yer/ que o/í/ su/son +1

9. ten $/ \mathrm{go} \mathrm{u} / \mathrm{na} \mathrm{es} / \mathrm{pi} / \mathrm{na} / \mathrm{cla} / \mathrm{va} / \mathrm{da}$

10.en/ me/dio/ del/co/ra/zón.

\section{RIMA RITMO}

$(1-4-7)$

(3-7)

$(2-4-7)$

$\begin{array}{ll}\text { b } & (2-4-7) \\ \text { A } & (2-7)\end{array}$

C (1-4-7)

d $\quad(2-4-7)$

c

d

$(2-7)$

\section{Esquema 5: Ritmo, rima y métrica}

(Fuente: Elaboración propia)

Los versos del poema son octosílabos. Los versos 6, 8 y 10 tienen siete sílabas pero como terminan con una palabra aguda se les suma una sílaba. Para determinar el patrón rítmico nos ayudaremos del siguiente cuadro: 


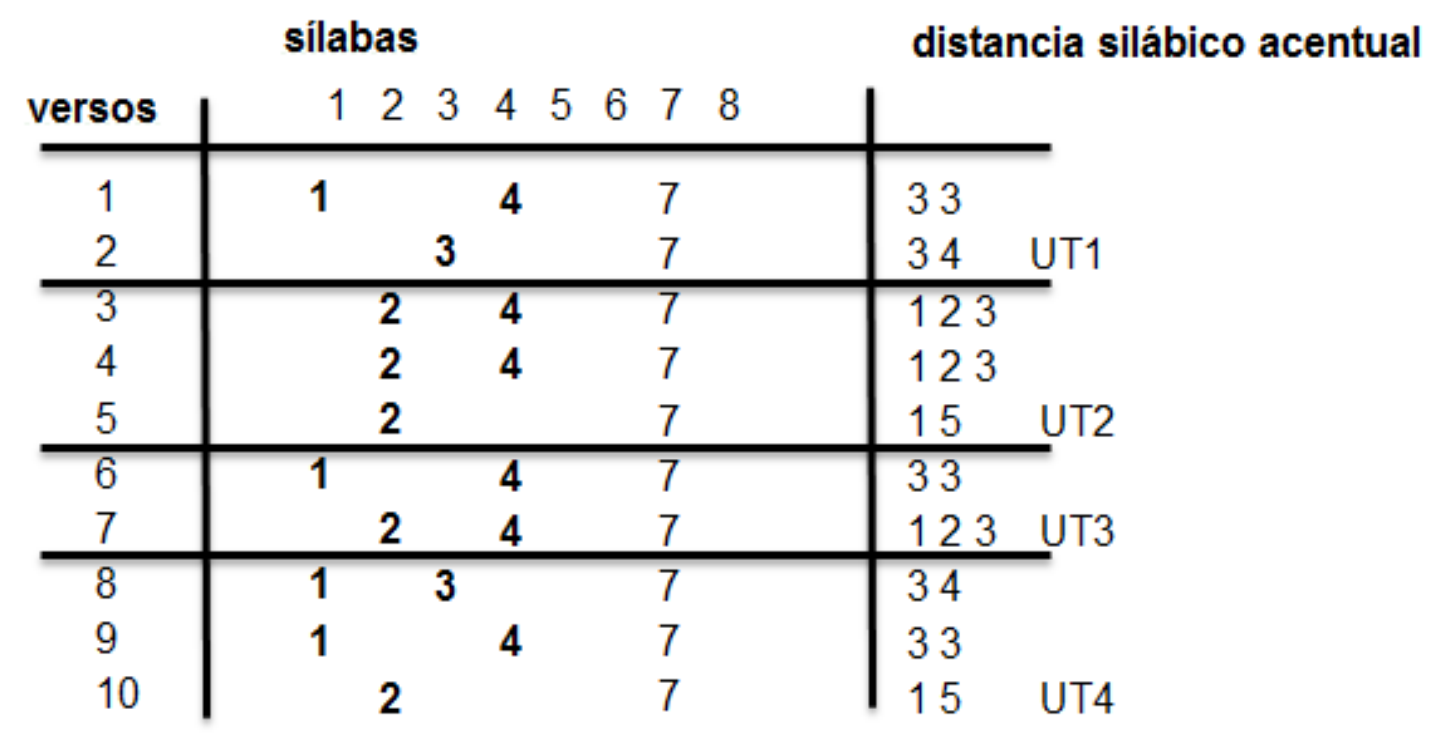

Esquema 6: Patrón rítmico

(Fuente: Elaboración propia)

Como podemos observar en el cuadro, el acento no siempre recae sobre las mismas sílabas numéricas a excepción de la 7. En la UT1 el primer verso es lento (tono dramático) y el segundo acelera, habla de un atributo positivo de la tranquilidad, que contrasta con ritmo rápido del verso. En la UT2, el ritmo 2-4-7 desacelera el discurso de los versos 3 y 4 que hablan de la herida. En la UT3 el ritmo de tres acentos desacelera, hace lenta la queja. El foco temático fluye con lentitud, así impresiona más. En la UT4, el ritmo de los versos 8 y 9 permanece lento, continua el tono de gravedad del foco temático, habla de la herida (una espina clavada). El verso 10 con ritmo 2-7 acelera al final, suaviza porque no se trata de una herida física sino de amor.

El ritmo sigue un patrón de tres acentos en sílabas iniciales (1 o 2), sílabas medias ( 3 o 4 ) y finales (7). La presencia de tres acentos en un verso lo hace lento y en él se tocan temas de gravedad (muerte, herida, tristeza, dolor). La supresión de acentos provoca el acelere del ritmo y se utiliza para tratar temas que suavizan o atenúan la gravedad de los versos lentos. Ritmo-tema es 
una dualidad que tiene marcado contraste con unidades de su misma naturaleza: lento / grave vs rápido / suave.

Los 5 primeros versos del poema conforman una unidad de rima consonante. Los versos impares riman entre sí por la terminación -eja y los versos pares por la terminación -ido. Los 5 versos restantes también conforman una unidad de rima consonante. Los versos impares riman entre sí por la terminación -on y los versos partes por la terminación -ada.

La pausa (,) que aparece en UT1 coincide con el final de ésta, sirve para dividir dos unidades temáticas. En UT2 la pausa tiene correspondencia con primer acento rítmico del verso tres y lo enfatiza. En UT3 los signos de exclamación pausan concediéndole al foco temático la independencia sintáctica y luego temática. El punto que aparece al final del verso 10 es la pausa que indica el final del poema.

Hemos visto, hasta el momento, cómo los puntos de análisis que se propusieron al principio del trabajo se estructuran y desarrollan en este poema de María Enriqueta. Las dualidades y oposiciones, la organizada estructura temática y el ritmo tan musical del poema implican una planeación del poema por parte de su autora. No podemos menos que señalar que lo que aparentemente era muy simple se sustenta en una intrincada red de elementos ordenados sistemáticamente: el manejo del tiempo, la relación causa-efecto, la relación entre las unidades temáticas y el orden cronológico, la relación entre ritmo y temas, y entre UT y etapas climáticas.

El detallado análisis del ritmo nos revela cuán importante era éste para la autora. Podemos apreciar que el ritmo es el elemento más relevante de todo el poema, como se planteó en un principio, tal vez debido a que la musicalidad era uno de los elementos que más importaba a los modernistas. Se marcaba el dominio de la forma sobre el contenido. Después de este análisis, hemos descubierto que el contenido no está tan relegado por la forma, sino que se encuentra perfectamente organizado independientemente de la sencillez del tema principal.

Podemos concluir afirmando que María Enriqueta Camarillo, una autora del siglo XIX, trabajó mucho a nivel estructural y semántico sus poemas en apariencia sencillos. Encontramos en ella una 
poética que nos remite al amor-dolor, asociado frecuentemente con la muerte, con el amor desdichado, con la represión a través del silencio porque amar al final de cuentas es angustiarse, callar, morir. Si se estudiara más su obra, quizás se descubriría que no merece pertenecer a las voces olvidadas sino a las estudiadas, comentadas y analizadas.

\section{Referencias:}

Contreras, R. (2000). Ni romántica ni modernista, mujer solamente: la poesía de Enriqueta Camarillo. Bulletin Hispanique, volumen 102 (1). Obtenida el 14 de octubre de 2018 de https://journals.openedition.org/bulletinhispanique/?lang=es.

Camarillo, M. E. (1984). "Tornó mi dolor". En Poesía Mexicana del Siglo XIX. México: Editorial Diógenes.

Echenique, M. et al. (1997). El análisis textual. Comentario filológico, literario, lingüístico, sociolingüístico y crítico. España: Colegio de España.

Páez Vivanco (1988), "La lógica de los mundos posibles y el concepto de isotopía”. Obtenida el 15 de octubre de 2018 de https://cdigital.uv.mx/bitstream/handle/123456789/6340/198820P73.pdf?sequence=2\&isAl lowed $=\mathrm{y}$

Robles, M. (1986) La sombra fugitiva, escritoras en la cultura nacional. México: UNAM. 